\title{
CONCUBINATO E UNIÃO ESTÁVEIS: DIREITO ROMANO E BRASILEIRO
}

\section{ARTIGO ORIGINAL}

DUARTE, Nayane Gonçalves dos Santos ${ }^{1}$

MORAIS, Carlos Nascimento de ${ }^{2}$

DUARTE, Nayane Gonçalves dos Santos. MORAIS, Carlos Nascimento de. Concubinato e União Estáveis: Direito romano e brasileiro. Revista Científica Multidisciplinar Núcleo do Conhecimento. Ano 05, Ed. 10, Vol. 09, pp. 114-128. Outubro de 2020. ISSN: 2448-0959, Link de acesso: https://www.nucleodoconhecimento.com.br/lei/concubinato-e-uniao

\section{RESUMO}

O presente artigo tem como objetivo apresentar uma interpretação referente ao concubinato e a união estável no direito Romano e Brasileiro. A expressão concubinato tem o significado atualmente de união paralela ou simultânea, sendo que no passado já significou a própria união estável em constituição de entidade familiar conceituado como família paralela, família simultânea, companheiros ou conviventes. Distinguir seus conceitos, aspectos históricos e legislações aplicadas, utilizando a apresentação de doutrinas e jurisprudências que tratam do tema abordado, no ordenamento Romano e Brasileiro. Descrever as formas de concubinato, apresentando como a questão tem sido resolvida nos tribunais superiores. Relatar as

1 Graduação em Direito pela Universidade de Fortaleza UNIFOR (2012). Tem certificado de pós-graduação nas áreas trabalhista e constitucional. Mestranda em Direito Constitucional, com ênfase nas relações privados da UNI7.

${ }^{2}$ Advogado, mestrando do Curso de Direito do Centro do Universitário 7 de Setembro (UNI7), pós graduado em Direito e Processo Tributário, pela Universidade de Fortaleza (UNIFOR). 
dificuldades que as pessoas que mantêm esse tipo de relacionamento encontram na legislação Brasileira. A doutrina, legislação e a jurisprudência defendem alguns direitos patrimoniais que irão ser tratados no presente trabalho, apontando quais os assuntos necessários para que aqueles que mantêm uma relação concubinária sejam amparados. A pesquisa utilizada foi a teórica, jurisprudencial e descritiva. Os métodos utilizados foram o indutivo, histórico e comparativo.

Palavras-Chave: Concubinato, União Estável, Efeitos Patrimoniais.

\section{INTRODUÇÃO}

O presente artigo versa sobre as relações de concubinos no cotidiano da sociedade, bem como as uniões estáveis, buscando na linha do tempo dessas relações que aos olhos da sociedade e do estado, sempre foram repudiados e negados na história. $\mathrm{Na}$ época do imperador Constantino as relações concubinárias chegaram a serem efetivadas em lei, logo em seguida com o surgimento do cristianismo a situação deixou de existir com a proibição da igreja. Mesmo assim, não desapareceu da sociedade. Atualmente, é mais fácil a resolução de conflitos envolvendo o concubinato, por meio de doutrinas e jurisprudências com entendimentos já pacificados.

Será traçado uma base histórica dessas formas familiares diversas da tradicional. Conceituando a união estável como uma relação, intima e informal, prolongada no tempo e assemelhada ao vínculo decorrente do casamento civil, entre sujeitos de sexos diferentes (conviventes ou companheiros), que não possuem qualquer impedimento matrimonial entre si. O termo é uma evolução jurídica do concubinato que surgiu no direito Romano.

Nesse contexto, passando pela classificação de formas familiares distintas, cada uma com sua peculiaridade, como por exemplo, a união homoafetiva por pessoas do mesmo sexo. Observa-se que, as formas familiares tradicionais ainda existem no século XXI, porém com o passar dos tempos, surgem outras formas de uniões, todas com o escopo em comum de uma busca pela felicidade. 
Tendo como objetivo analisar a problemática de como as pessoas que vivem em uma união estável, bem como as que mantém relações concubinárias são amparadas pela legislação Brasileira.

A pesquisa é importante para solucionar eventuais problemas advindos das formações familiares diversas da matrimonial, como o concubinato e união estável.

O artigo está dividido em três partes, além da introdução e conclusão. No primeiro tópico, serão pontuadas passagens históricas e conceitos de concubinato a luz do direito Romano, sua evolução e espécies.

Em seguida, são abordados os conceitos de união estável no direito Brasileiro, suas características e diferenças com a união concubinária.

Por fim, em um terceiro momento, expor os efeitos patrimoniais nas relações de concubinato e união estável, bem como, o entendimento jurisprudencial sobre a matéria.

No tocante à metodologia, a pesquisa foi realizada a teórica, jurisprudencial e descritiva, buscando através de doutrinas, jurisprudência e leis produzir o trabalho científico. Já os métodos utilizados foram o indutivo, trazendo jurisprudência sobre o tema e o histórico e comparativo, do conceito de concubinato no Direito Romano e Brasileiro.

\section{EVOLUÇÃO HISTÓRICA SOBRE CONCUBINATO NO DIREITO ROMANO}

No Direito Romano as existências das formas de uniões eram expressas de quatro maneiras, uma primeira delas sendo o jus civile, que formava a família legítima entre Romanos, a segunda seria a dos peregrinos entre peregrinos ou entre peregrinos $e$ Romanos, que viviam em sine connubio, de forma contrária aos ius civile, em terceiro destaca-se a união dos escravos que não possuía reconhecimento jurídico até a época do Imperador Justiniano contubernium, que Ihes concedeu alguns direitos; e, por último, a dos concubinos, que se relacionavam de forma livre. (AZEVEDO, 2002). 
Segundo Agerson Tabosa (2007, p.186), "A mulher, unida ao homem pelo concubinato, chamava-se concubina, amica, hóspita, focaria, mas não uxor. Também não era meretriz, em virtude da estabilidade e fidelidade da união. Com Justiniano, pode ela herdar 1/24 do patrimônio do varão com quem vivia." Acompanhando o entendimento do autor as concubinas tinham uma estabilidade e uma porção pequena de herança a herdar, observa-se alguns privilégios.

Assim, no direito Romano, o instituto chamado de concubinato, expressão que vem do latim cum (com) cubare (dormir), se apresentava entre a união de duas pessoas de sexos diferentes, como se fossem casados, caracterizando assim, como uniões livres, aquelas que não se prendem a formalidades exigidas pelo estado, ou seja, uniões não oficiais e com certa durabilidade com intuito de formar família, sem a affectio marital(vontade de estar casado) e a honor matrimonni(aparência de casamento).

Nesse contexto, observa-se que era um instituto familiar não vedado pela lei nem reprovado pela consciência social, tanto que pessoas de exemplar moralidade viviam em concubinato. O concubinato não foi reconhecido, porém teve ampla difusão em virtude das leis de Augusto (CARLETTI, 2000).

Destaca-se então, as leis matrimoniais de Augusto (lex iulia et papia poppaea de maritandis ordinibus), que criava rígidos impedimentos de natureza social a união com mulheres de situação social inferior e lex iulia de adulteriis. Como uma verdadeira forma de manter as linhagens e com uma visível discriminação de miscigenação com outras raças.

Conforme verificado, a lei não se tinha ocupado do concubinato, proibiram, por um lado, o casamento entre senadores e mulheres de certas categorias sociais (como, por exemplo, atrizes). Além disso, não poderiam se casar legitimamente, mas, sim, viver em comum, sem ser considerada uma prática criminal. Essas uniões extraconjugais lícitas eram as hipóteses em que se configuravam o concubinato. (ALVES, 2014, p.672). 
[...]após a era do imperados Augusto, nos últimos anos que se seguiram, tendo o imperador Constantino promulgado, em 326 d.C., um edito, em razão do qual a posição das concubinas e de seus filhos piorou em relação ao período anterior. E certo que os imperadores cristãos consideraram imoral o concubinato, tendo-o tolerado até o imperador Leão o sábio (886 a 912d.c.), definitivamente o aboliu (nov. 89,91). (AZEVEDO, 2002, p.152)

Nesse mesmo sentido, para incentivar as pessoas que viviam em um relacionamento concubino, o imperador Constantino sancionou; "[...] assim, criou sanções desestimuladoras do concubinato, procurando incentivar os concubinos a contraírem matrimonio, acenando-Ihes com a possibilidade de legitimação de seus filhos, para se submeterem ao poder paterno." (AZEVEDO, 2002, p.152).

Nesse viés, com o avanço do cristianismo, o imperador Constantino considerando o concubinato impuro, sancionou meios de punir as relações concubinárias para incentivar a o matrimónio. "Por sua vez, o imperador Justiniano, procurando limitar os números dessas uniões concubinárias, proibiu que o homem tivesse mais do que uma concubina e nenhum se fosse casado." (AZEVEDO, 2002, p.155)

Havia uma certa dificuldade pelos doutrinadores de conceituar o concubinato, não existindo um conceito preciso sobre o tema. "A partir da ideia central de uma convivência douradora entre um homem e uma mulher, sem casamento registrado (para usar o ordenamento jurídico soviético), que o direito vem por meio de uma história jurisprudencial, tentando clarear esse conceito." (PEREIRA, 2003, p. 40).

Cabe apontar que, existe duas espécies de concubinato mais citadas pela maioria dos autores, quais sejam, concubinato puro e concubinato impuro.

Assim, o concubinato puro; se apresenta quando existir uma convivência duradoura de um homem e uma mulher, sem restrições a outros casamentos, como é o caso dos viúvos, separados de fato, solteiros, casamento anulados, divorciados.

Segundo Álvaro Villaça (2002, p.190), "considera concubinato puro, quando ele se apresenta com os aludidos elementos do conceito expendido, ou seja, como uma 
união duradoura, sem casamento, entre homem e mulher, constituindo-se a família de fato, sem detrimentos de família legitima"

No mesmo sentido, traz o autor Roberto Senise (2013, p.197), "O concubinato natural ou puro, sem estabilidade, porem motivado por atos esporádicos ou uniões livres, ainda que frequentes, não é considerado equivalente a união estável, pois ela se caracteriza pela união informal de pessoas de sexos diferentes, prologada no tempo"

Já o concubinato impuro; fazia referência ao adulterino quando se envolviam pessoas casadas em outro relacionamento, ou seja, os que mantinham mais de uma união de fato. "Concubinato espúrio ou impuro é aquele efetivado entre pessoas de sexos diferentes, de forma estável, porém com algum impedimento para realização do casamento civil. Pode ser classificado em duas, concubinato adulterino e concubinato incestuoso" (LISBOA, 2013, p.197).

Diante do exposto, como já citado existe outras espécies de concubinato; eg:; adulterino, "Concubinato adulterino, antes a existência de impedimento matrimonial de, ao menos, um dos concubinos, que se encontram casados civilmente com outra pessoa." (LISBOA, 2013, p.197), e o incestuoso "Concubinato incestuoso, decorrente do parentesco próximo entre os concubinos, que pudesse impedir o casamento civil deles." (LISBOA, 2013, p.197), Esse era repudiado e proibido até a contemporaneidade.

Já para Agerson Tabosa (2007, p.175); existe outra figura chamada de "sacrílego Se o impedimento fosse de ordem religiosa, se o pai ou a mãe, ou ambos, tivessem feito votos de castidade, o filho dessa união se chamaria sacrílego. O direito Brasileiro moderno não configura esse caso."

O nosso texto constitucional Brasileiro de 1988 denominou o concubinato de união estável, numa expressão que traduz, na atualidade dessa instituição tão antiga e tão atual. (PEREIRA, 2003, p.41). Nesse mesmo sentido,

Com o advento da constituição da república, propiciamente apelidada de "constituição cidadã" o velho concubinato foi elevado à altitude de 
entidade familiar, passando a se submeter à normatividade dos direitos das famílias e, principalmente, ganhando especial proteção do estado a mesma dispensada ao casamento. Por óbvio, o concubinato o concubinato que foi alçado à caracterização de família foi o "concubinato puro" passando a ser chamado de união estável, exatamente com a intenção de evitar estimas ou preconceitos. (FARIAS; ROSENVALD, 2017, p.462)

Como se observa o presente tópico, trata de concubinato no Direito Romano, sendo comparado com o Direito Brasileiro, já que a união estável que trataremos no próximo tópico, é uma evolução jurídica do Direto Romano.

\section{CONSIDERAÇÕES INICIAIS SOBRE UNIÃO ESTÁVEL E DIREITO CIVIL BRASILEIRO}

Feito a conceituação e apresentação da evolução jurídica do concubinato no direito Romano, passa-se a analisar a figura da união estável no direito Brasileiro, figura admitida no ordenamento, com direitos amparados.

Como já citado a figura da união estável deu ensejo em 1988 na Constituição Federal, resumo legislativo inserido por Agerson Tabosa "Até 1977, só existia no Brasil, sob proteção do Estado, um tipo de família, a família legítima, constituída pelo casamento civil, indissolúvel. Somente em 1977 é que o divórcio veio, introduzido pela Emenda Constitucional." (2007, p.67). Emenda Constitucional essa que, foi sancionada como lei no decorrer do mesmo ano da sua inclusão assim, passou a abranger a união estável como família legitima, mesmo com a ausência do casamento civil.

Diante disso, em um primeiro é essencial adentrar com o conceito "A união estável é a relação, intima e informal, prolongada no tempo e assemelhada ao vinculo decorrente do casamento civil, entre sujeitos de sexos diferentes (conviventes ou companheiros), que não possuem qualquer impedimento matrimonial entre si." (LISBOA, 2013, p.193).

Para o autor Dimas Messias (2018, p.54); "A família convencional é a constituída fora do casamento pela união estável, caracterizada pela união informal pública, duradora 
e continua do homem e da mulher. Até a constituição de 1988 não possuía previsão legislativa"

$\mathrm{Na}$, perspectiva sociológica, a família é uma instituição permanente, mutável em suas características estruturais em face do tempo, e hoje integrada por pessoas cujos vínculos derivam da união estável, da procriação e do parentesco (PESSOA, 1997).

Nos dias atuais quando nos referimos ao concubinato no Brasil, de uma forma ampla sem as modalidades de impuro ou puro, é unicamente o relacionamento amoroso envolvendo pessoas casadas, que não cumprem o dever de fidelidade (adulterino), também conhecido como "amantes". "Ao acolher a união estável como entidade familiar, a constituição adotou a orientação de Álvaro Villaça (estatuto da família de fato) de proteger o concubinato não adulterino e não incestuoso." (LISBOA, 2013, p.194)

Nesse sentido, amante, é aquele que vive com homem ou mulher casado ao mesmo tempo com o cônjuge, não estando separado de fato, mantem relação afetiva e vive com os dois relacionamentos, logo existe as famílias paralelas. (CARVALHO, 2018)

No âmbito penal, nunca o relacionamento livre entre homens e mulheres foi tratado como crime ou ato ilícito, mas as suas consequências se projetavam, tão só, no âmbito do direito das obrigações, afastando do direito das famílias. (FARIAS, 2017).

Seguindo a ideia de união estável ser aceita e amparada no Brasil, existe alguns requisitos para se caracterizar uma união estável, concubinato não adulterino e não incestuoso, entre eles citaremos:

A diferença de sexo; Ausência de matrimonio e impedimento matrimoniais; Notoriedade de aferições reciprocas (convivência more uxório deve ser notória, devendo se tratarem como marido e mulher, teoria da aparência, mesmo que não haja prole em comum, mas que demostre 0 interesse de ter vida em comum); Honorabilidade (união respeitosa entre homem e mulher, pautado na affectio e no animus de constituir uma família); Fidelidade ou lealdade (não havendo fidelidade ou relação monogâmica, o relacionamento passa a status de "amizade colorida", sem ter 
união estável. Podendo ter uma união estável putativa, quando a pessoas e enganada na relação achando ser a única pessoa da vida do seu companheiro (nesse caso a jurisprudência aceita e indeniza a pessoa lesada nos moldes da união estável); e “Coabitação”. (LISBOA, 2013, p.194)

Sobre a coabitação tratada por alguns autores, a súmula 382 do Supremo Tribunal Federal, nesses termos fala: "A vida em comum sob o mesmo teto, more uxório, não é indispensável à caracterização do concubinato." Ou seja, existe casais que vivem em residências diferentes, pois seus trabalhos para custear as despesas do lar, são em localização distinta, isso não excluiria o status de união estável,

[...] Sim, porque no direito de família não se cuida da rígida ideia de domicilio, mas do sentido do lar, que é o local de encontro da família, onde, na intimidade, se exercem, de modo duradouro, as relações familiares. Assim, é não só no casamento, como no concubinato. (AZEVEDO, 2002. p.214)

A população Brasileira está em constante mudanças e com isso vem surgindo várias formas de famílias. Como por exemplo, Família anaparental, adotiva, poliafetiva, natural ou nuclear, extensa ou ampliada, família substituta, adotiva, mosaico ou reconstituída, eudomonista, democrática, multiparental ou pluriparental, binuclear, paralela, poliafetiva, online ou ifamily, ectogenético. Trabalharemos alguns conceitos; União estável, Homoafetiva, monoparental, matrimonial e putativa.

Iniciando com união estável de pessoas do mesmo sexo, também clamada de isossexual (do grego iso, igual), tinha o mesmo direitos e deveres união estável heteroafetiva, ainda que não prevista na constituição federal, não pode ser excluído do status de família a ser merecedora da proteção do estado. (CARVALHO, 2018).

Continuando a linha de raciocínio de Dimas Messias (2018), nas uniões homoafetivas, isto é, formado por pessoas de sexos iguais, homem com homem ou mulher com mulher, mesmo sem previsão expressa na Carta Magna, e protegida como uma formação familiar com direitos assegurados igualmente das uniões heteroafetivas. 
Família constituída por um do ascendente ou descendentes, "Família monoparental, é a entidade familiar constituída por um ascendente e o seu descendente" (LISBOA, 2013, p.233)

Uniões civis reconhecidas pelas normas Brasileiras, ou seja, casamento civil, "Família matrimonial, e formada com base no casamento civil pelos cônjuges, incluindo, não necessariamente, a prole, natural ou socioafetividade. É uma união legal vinculada a normas cogentes, vivendo em plena comunhão de vida e em igualdade de direitos e deveres." (CARVALHO, 2018, p.53)

Outras formas familiares que causam bastantes discursões são as uniões estáveis putativa, Segundo Dimas Messias (2018, p.495-496), “A união estável putativa; pode ocorres quando um ou ambos concubinatos não sabem dos impedimentos para o casamento." Ainda que exista concubinato nesses termos será aplicado todos os efeitos da união estável.

Art. 1.561. Embora anulável ou mesmo nulo, se contraído de boa-fé por ambos os cônjuges, o casamento, em relação a estes como aos filhos, produz todos os efeitos até o dia da sentença anulatória. § 10 Se um dos cônjuges estava de boa-fé ao celebrar o casamento, os seus efeitos civis só a ele e aos filhos aproveitarão. § 20 Se ambos os cônjuges estavam de má-fé ao celebrar o casamento, os seus efeitos civis só aos filhos aproveitarão. (BRASIL, ONLINE)

É importante ressaltar que, falar sobre amparo legal e evolução jurídica, no direito Brasileiro, deve citar o código civil de 1916, trazendo o concubinato como uma maneira marginal o que perdurou até o código civil de 1932. Foi por intermédio das jurisprudências que aos poucos o tema foi tomando espaço no nosso ordenamento.

Com a necessidade da regulamentação dos relacionamentos concubinários e união estável. Foi aprovada a Lei no. 8.971 de 20 de dezembro de 1994 (que definiam como "companheiros", homem e mulher com mais de 5 anos ou com prole - concubinato puro). Já a Lei no .9.278 de 10 de maio de 1996, tentando regulamentar o que já tinha sido trazido pela constituição federal no seu art. 226 (alterou o conceito de companheiro para "conviventes", omitindo o tempo mínimo e existência da prole). 
Diante dos furos, imperfeições e contradições destes textos acimas mencionados, o poder executivo apresentou um projeto no Congresso Nacional, numa tentativa de se fazer um estatuto para o concubinato.

No final de 1996, foi apresentado novo projeto de lei, PL. n. 2.696/96 - elaborado pelo ministério de justiça com a participação de notáveis juristas, sendo conhecido como estatuto da união, e que pretendia regular a união em todos os sentidos, com novo conceito, direitos e deveres, regime legal e convencional de bens, relação com terceiros, alimentos, direitos sucessórios, usufruto, vocação sucessória e conversão em casamento. (CARVALHO, 2018)

Finalmente o código civil de 2002, antes da aprovação do estatuto, supriu a omissão do código anterior e regulamentou a união estável nos art. 1.723 a 1.727, reconhecendo o concubinato puro, denominando-o união estável (art. 1.723). (CARVALHO, 2018)

Já o concubinato impuro é denominado somente concubinato no Código Civil art. 1.727. Ou seja, toda relação advindo de uniões não acidental entre mulheres e homens com impedimentos matrimoniais formam um concubinato.

Finalizando alguns conceitos e evoluções jurídicas sobre o assunto, trataremos em seguida dos efeitos patrimoniais advindos dessas relações.

\section{EFEITOS PATRIMONIAIS NAS RELAÇÕES DE UNIÃO ESTÁVEL E CONCUBINATO}

Igualmente o que ocorre no casamento, no fim da união estável gera diversos efeitos que vão além da ruptura dos laços afetuosos e que interferem de forma direta na esfera patrimonial dos envolvidos.

Sobre o assunto, este é tratado na Constituição Federal no art. 226, $\S 3^{\circ}, 2^{\underline{a}}$ parte, não pleiteou a edição de leis substantivas que conferissem direitos e impusessem deveres aos conviventes como se a união estável fosse idêntica ao casamento, mas sim de 
normas adjetivas que viessem a simplificar ou facilitar procedimento para conversão da união estável em matrimônio.

Vale salientar que, os mesmos direitos inerentes ao casamento, sobre o regime de comunhão parcial de bens é aplicável a união estável. Segundo Roberto Senise (2013, p. 211), "Aplica-se às relações patrimoniais entre os conviventes, no que couber, o regime de comunhão parcial de bens."

Seguindo a linha de raciocino do parágrafo anterior, a Lei ํㅜ 9.278/96, em seu art. 5으, supriu a lacuna da Lei no 8.971/94. Assim os bens adquiridos por títulos oneroso e os bens adquiridos posterior à o início da união de forma unilateral ou pelo casal na duração, serão bens comuns do casal, ou seja, regime similar da comunhão parcial de bens. Também chamado de condomínio da união estável, com exceção as uniões advindas de contrato escrito previamente estipulado, ou que tenha sido adquirido antes da união. Não se comunicam as doações exclusivas a um deles e a herança.

O autor Roberto Senise (2013, p. 213) "O convivente tem direito à indenização por morte do outro convivente, no caso de acidente de trabalho ou de transporte". Conforme o entendimento da súmula 35 do Supremo Tribunal Federal: "Em caso de acidente do trabalho ou de transporte, a concubina tem direito de ser indenizada pela morte do amásio, se entre eles não havia impedimento para o matrimônio" (BRASIL, Online). Entendimento já pacificado de modo que, o concubinato citado na referida súmula trata das uniões estáveis sem impedimentos ao casamento.

Nesse mesmo sentido, advém os direitos sucessórios. Quando pela morte de um dos companheiros, o outro terá o direito de acionar o estado para obtenção da herança, bem como a sua meação, a moradia e os eventuais privilégios previdenciários, sem que com isso seja prejudicado na sub-rogação de contrato locatício de imóveis urbanos. (FARIAS; ROSENVALD, 2016).

Sobre o assunto, a Lei ํㅜ 9.278, de 10 de maio de 1996, art. 7º, ampara as pessoas que perderam seus companheiros em virtude de morte, isto é, protege-se os companheiros com assistência material, alimentos e moradia da familiar. Tendo sido 
a união estável (união livre entre homem e mulher) elevada à condição de entidade familiar, e com isso todos os direitos equiparados, resta tratar do concubinato adulterino.

Sobre esse direito em relação ao concubino adulterino, "[...]contra os interesses da concubina. Mesmo perante a nova legislação civil, ademais, a concubina não pode receber qualquer bem de seu amásio, se casado for, porque há entre ela e o doador, nesse caso, impedimento matrimonial." (LISBOA, 2013, p.212)

Segundo Dimas Messias (2018, p. 493), "Os entendimentos atuais tanto do superior tribunal federal como do superior tribunal de justiça, é no sentido de não reconhecer efeitos jurídicos de direito de família ao concubinato. Mas essa interpretação não é absoluta."

Se tratando de filhos comum, "[...]quando envolver filhos comuns dos concubinos, os direitos. Nesta dimensão, as relações entre pais e filhos são em tudo iguais às de qualquer entidade inclusive do casamento e da união estável." (LÔBO, 2011, p.186)

Segundo a sumula 380 STF: "Comprovada a existência de sociedade de fato entre os concubinos, é cabível a sua dissolução judicial, com a partilha do patrimônio adquirido pelo esforço comum."

Em suma, os concubinos terão direito de meeiros, como uma partilha de condomínio, isso é, recebera a porcentagem que contribuiu na compra do referido bem, devendo as mesmas recorrerem ao direito de obrigações como sociedade de fato para regularização e divisão, fora do direito de família.

Segundo Álvaro Azevedo (2002), sobre os direitos do concubinato impuro, conclui-se que, embora exista várias transformações antes e depois da constituição Federal de 1988, os envolvidos nessas relações continuam inseguros sobre seus direitos, sendo algo proposital do legislador, no sentido de que, por mais liberal que seja essas relações não deve desrespeitar o primeiro relacionamento de boa-fé ou prejudicá-los com enriquecimento ilícitos e desproporcionais, não se confundindo com a união estável. 
Assim, as partilhas de bens advindas dessas relações, se aplicam a comprovação de adquirir os bens decorrente de trabalho comum para sua efetivação e os mesmos devem ser solicitados em regra na seara de direitos obrigacionais.

Diante disto percebe-se que os entendimentos atuais, mesmo com as constantes mudanças nas formações familiares, diversas da matrimonial entre homem e mulher, preserva-se o entendimento da existência da união de fato em desfavor das relações paralelas, que dizer, concubinato não tem direitos patrimoniais, a não ser o caso de união estável putativa, boa-fé de um dos envolvidos ou de ambos, como foi um caso já registrado de casamento entre irmão, sem saber que eram irmãos.

\section{CONCLUSÃO}

Conclui-se que, as formas famílias no contexto Brasileiro, vêm se modificando no dia a dia. Nisso, os conceitos inseridos no início da época do cristianismo no direito Romano, formando basicamente uniões monogâmicas, entre homem e mulher, com matrimônio civil, no século XXI já não se observa com tanta frequência essas uniões.

Fica evidente, diante desse quadro, que os avanços e alterações da nossa sociedade vem surgindo com novos campos de formação familiar, como o da afetividade, relacionamentos a distância, seja por meio de união estável de pessoas de sexos diferentes ou iguais, com fim de relacionamentos anteriores uma reconstrução de novas famílias, anaparental sem a presenta afetiva dos pais biológicos, dentre inúmeras formas afetivas de família com ou sem vínculo de parentesco ou consanguíneo.

Contudo, a família Brasileira contemporânea se estabelece as bases na pretensão de seus participantes, que não se limitam somente as editadas pelo estado, mas sim à afetividade, que com outros princípios basilares, como a felicidade, respeito, liberdade e bem estar, formam o grande núcleo principal no contexto familiar.

Sendo assim, a união estável antes conceituado como concubinato puro, tem os mesmos efeitos das relações matrimoniais, com leis especificas para resguardar os 
envolvidos nessas relações. O concubinato que sempre esteve forte em nossa sociedade, inclusive no direito Romano, antes sem nenhum efeito ou lei protetiva, hoje se mantém como família paralela, onde a pessoa não abandona seu relacionamento atual, mas mantém de forma simultânea outras relações, devendo-se observar que, a essa segunda união acontece de desconhecimento da primeira união para ter efeitos familiares.

Fica evidente diante desse quadro que, a união estável se diferencia do concubinato, no momento em que a primeira relação se efetiva sem impedimentos matrimoniais, podendo um dos envolvidos ser casado no papel, porém separado de fato, se enquadrando em uma nova união e por ventura ser protegido pelo direito de família.

Por outro lado o concubinato existe concomitantemente ou de forma paralela com um matrimônio, sendo essa uma relação extraconjugal, sem amparo do direito de família contudo existe exceção, exemplo do caso da união estável putativa, aparentemente vive em uma relação concubinária, porem um dos envolvidos desconhecia o status de casado do companheiro e por ventura foi enganado, ai sim, o entendimento majoritário segue em proteção hereditária e partilha em cima do que foi construído com esse relacionamento.

É evidente que, deve-se amparar e proteger essas uniões paralelas independentes de serem formadas em contexto diverso das fixadas na lei vigente.

Já no contexto do concubinato impuro ou adulterino, ou seja, que existe quando alguém mantém uma entidade familiar advinda de um concubinato com pessoas impedidas de casar, como os já casados civilmente. Conclui-se que, não devem ser reconhecido os direitos das pessoas que vivem em concubinato adulterino, visto que, existe impedimentos de relacionamentos anteriores, não sendo uma forma legítima de formação familiar, já que a outra parte tem impedimento.

Devendo ser mantido as relações paralelas no direito das obrigações, pois o concubinato adulterino não se trata de união familiar, não tendo qualquer direitos sobre bens há não ser os bens que adquiriu conjuntamente com seu "amante", não 
devendo ser retirar da companheira ou esposa os bens que trabalhou e contribuiu para adquirir.

Assim, observa-se que existe diversos problemas na resolução dos litígios com o fim desses relacionamentos. Contudo, nota-se que tem várias decisões divergentes sobre o assunto nos tribunais, em virtude da ausência de normas específicas que passem a dispor de todas as entidades familiares existentes independentemente de sua composição, que de modo injusto ou justo e com preconceitos na sua formação ou não, ficam prejudicados nos julgamentos, porém cada caso é um caso, devendo ser analisado individualmente.

Finalizando, muitas instituições recorrem ao direito civil que é de origem Romanísticas, demostrando e servindo de comprovação de como o direito é um produto histórico.

\section{REFERÊNCIAS}

ALVES, Jose Carlos Moreira. Direito Romano. 16. ed. Rio de Janeiro: Forense, 2014.

AZEVEDO, Álvaro Villaça. Do concubinato ao casamento de fato. 1986. Tese (doutorado - faculdade de). Belém: Cejup, 1986.

AZEVEDO, Álvaro Villaça. Estatuto da Família de fato: De acordo com o novo código civil, lei no 10.406, de 10-01-2002. 2. ed. São Paulo: Atlas, 2002.

BRASIL. Constituição (1988). Constituição da República Federativa do Brasil. Brasília, DF: Senado Federal, 1988.

Lei n. 9.278, DE 10 DE MAIO DE 1996. Regula o $\S 3^{\circ}$ do art. 226 da Constituição Federal. Diário Oficial da União, 10 de maio de 1996. Disponível em: http://www.planalto.gov.br/ccivil_03/LEIS/L9278.htm. Acesso em 05 de maio de 2020.

. Lei n. 10.406, de 10 de janeiro de 2002. Institui o Código Civil. Diário Oficial da União, 11 de jan. de 2002. 
. Superior Tribunal de Federal. Súmula no 35. Em caso de acidente do trabalho ou de transporte, a concubina tem direito de ser indenizada pela morte do amásio, se entre eles não havia impedimento para o matrimônio. Brasília, DF. Disponível em: http://www.stf.jus.br/portal/jurisprudencia/menuSumarioSumulas.asp?sumula=3074. Acesso em: 05 de maio de 2020.

Superior Tribunal de Federal. Súmula $\mathbf{n}^{\circ} \mathbf{3 8 0}$. Comprovada a existência de sociedade de fato entre os concubinos, é cabível a sua dissolução judicial, com a partilha do patrimônio adquirido pelo esforço comum. Brasília, DF: Superior Tribunal de federal, [2002].

Disponível em:http://www.stf.jus.br/portal/jurisprudencia/menuSumarioSumulas. asp?sumula=24 82. Acesso em 28 de abril de 2019.

Superior Tribunal de Federal. Súmula n. 382. A vida em comum sob o mesmo teto, more uxorio, não é indispensável à caracterização do concubinato. In: Súmulas.

Brasília-DF. 1964.

Disponível em: http://www.stf.jus.br/portal/jurisprudencia/menuSumarioSumulas.asp?sumula=2488. Acesso em: 05 de maio de 2020.

CARLETTI, Amilcare. Curso de Direito Romano. São Paulo: Universitária de direito, 1999.

CARVALHO, Dimas Messias de. Direito das famílias. 6. ed. São Paulo: Saraiva Educação, 2018.

DINIZ, Maria Helena, Curso de Direito civil Brasileiro. Vol. 5. 28. ed. São Paulo: Saraiva, 2013.

FARIAS, Cristiano Chaves de; NELSON, Rosenvald. Curso de Direito Civil: Famílias. 9. ed. Salvador: Juspodivm, 2016. 
GAGLIANO, Pablo Stolze, RODOLFO, Pamplona Filho. Novo curso de direito Civil, volume. 6: Direito das famílias - As famílias em perspectiva constitucional. 3 ed. rev. atual e ampl. São Paulo, 2013.

GONÇALVES, Carlos Roberto. Direito Civil: Direito de Família, volume 2. 7 ed. rev. São Paulo: Saraiva, 2000.

LISBOA, Roberto Senise. Manual de direito civil: direito de família e sucessões. 8. ed. São Paulo: Saraiva, 2013.

LÔBO, Paulo. Direito civil: Família. 4 ed. São Paulo: saraiva, 2011

MARTINEZ, Jesús Daza; ENNES, Luis Rodríguez. Instituciones de Derecho Privado Romano. 4. edición. Valencia: Editorial Tirant lo Blanch, 2009.

PEREIRA, Rodrigues da Cunha. Direito de Família: uma abordagem psicanalítica, 2. ed. Ver. Atual, ampl. Belo Horizonte: Del Rey 2003

PESSOA, Claudia Grieco Tabosa. Efeitos patrimoniais do concubinato. São Paulo: Saraiva, 1997.

PINTO, Agerson Tabosa. A união estável Brasileira e suas raízes romanísticas. Revista Jurídica Da FA7, v. 4, p. 65-79, 2007. Disponível em: https://periodicos.uni7.edu.br/index.php/revistajuridica/article/view/201. Acesso em: 01 de maio de 2020.

TABOSA, Agerson. Direito romano. 3. ed. Fortaleza: fa7, 2007

Enviado: Maio, 2020.

Aprovado: Outubro, 2020. 